\title{
THE COMPLICATIONS OF INFLUENZA
}

\author{
C. H. Stuart-HaRris, C.B.E., M.D., F.R.C.P. \\ Professor of Medicine, University of Sheffield
}

EPIDEMIC influenza has been characterized throughout history by its ability to kill. The extent of this mortality has, of course, varied from outbreak to outbreak so that it is impossible to provide any meaningful statistics. Indeed, so far as the entire country is concerned, the number of deaths appears to be determined as much by the total morbidity as by the time of year of the outbreak or the particular population group. Kilbourne (1960) has gone so far as to suggest that the influenza virus has not altered appreciably in regard to its intrinsic virulence for man in the past 50 years, morbidity being determined by immunological factors and mortality by abnormalities of the host or his environment. This is a suggestion which might well occasion a heated debate particularly as we have yet to decide upon a laboratory method of defining virus virulence which would enable us to classify strains. It is, however worthwhile emphasizing the point which emerged abundantly during the first waves of the $\mathrm{A} 2$ influenza era, namely that complications then occurred particularly among those in the older age-groups with chronic disease of the heart or lung. The host appears therefore to be all important in the determination of the incidence of fatal complications of influenza. This was indeed obvious even before the Asian virus era, for during influenza epidemics deaths from all causes rise and although the largest separate increase is in respiratory complications, deaths due to hypertension, rheumatic heart disease, chronic nephritis, and diabetes, all show an increase often known as the excess mortality of influenza. The ages of those who died during 1957 in the Asian outbreak of the U.S.A. were such that over one-half of the excess mortality occasioned by the OctoberDecember wave occurred in those over 65 years of age and the proportion of these rose to $80 \%$ in the third wave of January-March 1960 (Eickhoff, Sherman, and Serfling, r96r).

\section{The Respiratory Complications of Influenza}

The most important complications are those involving the lower respiratory tract which may be divided into cases of tracheobronchitis and bronchiolitis and those with pneumonia. The distinction of the bronchitis patients from those with uncomplicated influenza may be difficult to make and is in any case somewhat artificial. Because we have lacked information on the pathology of human influenza in the past, it is difficult to know the exact area of the respiratory tract affected by virus lesions. Thus although theo focus is usually assumed to be the nasopharynx and듬 nasal turbinates, the high proportion of patients $\overline{\bar{c}}$ with cough and the frequent occurrence of $\mathbb{Q}$ substernal soreness or huskiness of the voices suggest that the virus does not limit its attack to the upper respiratory tract. Burnet indeed often. writes of influenza as essentially a disease of the $\overrightarrow{\vec{H}}$ bronchial epithelium and thinks of spread as $\omega$ occurring primarily in an upward direction? Recent work published by Walsh, Dietlein, Low, 3 . Burch and Mogabgab (r96r), which was based w upon tracheal and bronchial biopsies obtained by bronchoscopy in six patients with uncomplicated influenza, certainly seems to confirm at least the presence of epithelial lesions. There are noo clinical signs of this tracheo-bronchitis in simple음 influenza but the frequent development of added sounds in the chest and even the raising of sputum? in previously healthy persons is a pointer in the 0 ? same direction. In 1937 , I found rales or rhonchi $\mathbb{Q}$ in 53 of 82 patients $(64 \%)$. Of the 53 , 19 patiengs $\overrightarrow{\vec{\theta}}$ showed abnormalities for several days, such fine or medium basal râles with or withoưt ${ }^{\text {. }}$ rhonchi elsewhere (Stuart-Harris, Andrewes and Smith, I938); $31 \%$ of the patients produced sputum in the form of pellets or nummules of white to green mucopus. All these abnormalities: were found in patients thought to have uncomplic- $\propto$ ated disease except that in one patient previously $\overrightarrow{0}$ affected by asthma, generalized wheezing rhonchi 3 indicated that a general broncho-constriction had $\mathcal{F}$ occurred. It is, in fact, the asthmatic patient who? during influenza develops wheezing rhonchio suggesting widespread bronchial involvement, and 3 . a similar picture occurs in the ordinary case $\frac{3}{3}$ of chronic bronchitis. Much more serious are the cases of severe laryngo-tracheo-bronchitis which occur relatively infrequently but which were seen in schoolchildren during the first Asian 을 epidemic. Obstruction in these cases was severe $\frac{7}{0}$ enough to necessitate tracheostomy.

Influenzal bronchiolitis is characterized by aN more prolonged pyrexia than the ordinary case, by dyspnœa and slight cyanosis and by abundant $O$ râles varying from fine to coarse over wide areas $\omega$ of the lung. Cough is productive of a muco- -2 purulent or frankly purulent sputum. Sometimes ${ }^{\circ}$ the sputum is viscid, the bronchioles are plugged $\mathbb{\Phi}$ with secretion, and breath-sounds over the affected $\stackrel{?}{?}$ area are reduced. The radiograph is essentially $\frac{0}{0}$ normal. Virus is readily demonstrable in patients $\frac{\vec{D}}{\mathrm{D}}$ with bronchiolitis, for the air-passage involve- $\frac{\rho}{\mathcal{Q}}$ 
ment occurs synchronously with the disease. The sputum does not usually contain pneumococci but Hamophilus influenzae may or may not be present. In a series of 17 cases of bronchiolitis seen in 1937 the past histories of the patients were examined carefully in order to determine whether the complication was the result of previous chest disease. Four patients only gave a history of such illness; two had had previous bronchitis, one an attack of pneumonia in childhood and one had pleurisy a year before the influenza. Perhaps the important fact is that I 3 patients had no previous chest abnormality and that influenzal bronchiolitis ought to be regarded as a feature of the virus infection in previously well adults.

Influenzal pneumonia is of two main varieties occurring respectively synchronously with and after the influenza virus infection. The clinical picture first of all of post-influenzal pneumonia is little if at all different from ordinary pneumococcal pneumonia. These are the patients who have been up for a day or two or are about to be discharged and who develop a sudden pleural pain, fever and dyspnœa. They are perhaps iller than most cases of pneumococcal pneumonia at times other than during epidemics of influenza. They tend to have classical signs of consolidation, pneumococci are the chief cause of the condition and chemotherapy is eminently satisfactory. The synchronous cases of influenzal pneumonia are a different problem. These patients begin to be ill with the normal symptoms of influenza but soon become dyspnœic and cyanosed. Chest pain of a pleural character may or may not be present. Cough is often present but may be unproductive in spite of abundant râles in more than one area. The appearance of severe illnesses and the fact that the patients are often mentally disturbed and disorientated are points of distinction from cases of uncomplicated influenza. The pulse also is usually rapid, the blood pressure low, and the patient may be sweating and thus present the appearance of shock.

The clinical picture is seen in its most striking form in patients who become gravely ill within a matter of 36 hours of the onset of illness. Such fulminant pneumonia is characteristic of staphylococcal infection.

Table I shows the bacteria recovered from cases of all varieties of pneumonia admitted to hospital under my care during the AI virus era (StuartHarris, 1953). The non-influenzal periods consisted of one of three months and one of six months during which 130 cases of pneumonia were investigated; 166 cases of pneumonia were studied in two separate influenzal Ar periods of three months' duration. The great difference between the bacteria concerned in these two seasons is, of course. the increase in number of staphylococcal cases. It is, in fact, the Staphylococcus pyogenes which constitutes the main bacterial threat to cases of influenza in this day and age. This is well shown by the species of bacteria recovered from the sputum or lung of fatal cases of pneumonia during the first Asian wave in England and in Holland (Report of the Public Health Laboratory Service, 1958; Hers, Goslings, Masurel and Mulder, 1957). In both series of cases there were a number of fatalities in which no pathogenic bacteria were recovered from the lung. The Leyden workers (Hers, Masure? and Mulder, 1958) have made an excellent study of such cases and have proved to my mind conclusively that virus alone can cause an actual pneumonitis. The most important pathological findings are that the alveolar cells are desquamated and necrotic and the pulmonary capillaries show thrombosis, necrosis and hæmorrhage; in addition there is a hyaline membrane which lines the alveolar ducts and alveoli. It seems strange that the best demonstration of this lesion, proven as viral by means of staining with fluorescent-

TABLE I

Bacteria Recovered in Cases of Pneumonia in Sheffield (Influenzal and Non-influenzal Periods)

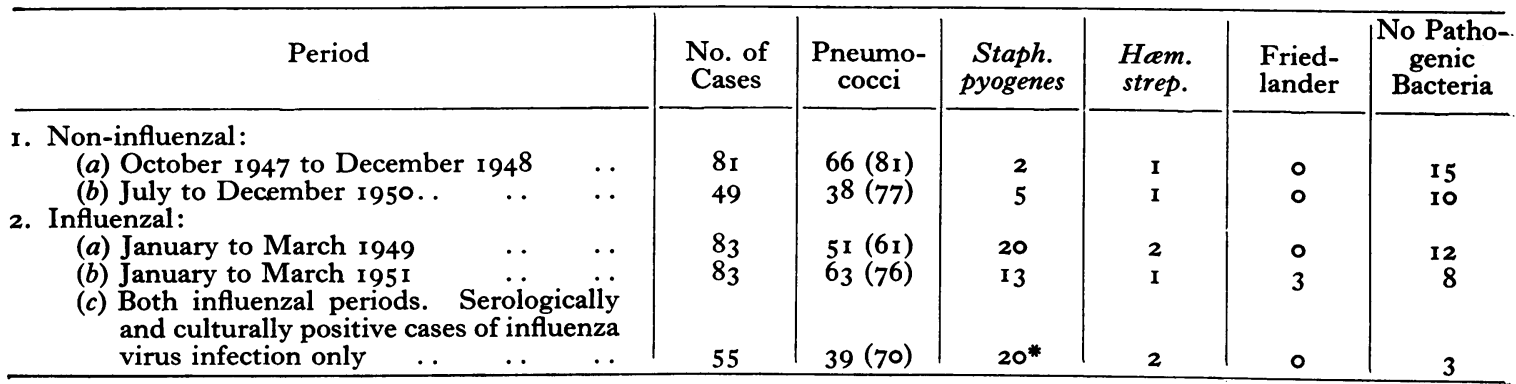

* 7 had pneumococci as well. (Figures in brackets are percentages.) 
tagged immune serum, has been obtained in patients with mitral stenosis. Superadded to this virus lesion are the necrotizing and toxic effects of the carpet of staphylococci which extends from the larynx down to the alveoli in those patients who die from influenza-staphylococcal pneumonia.

One cannot conclude this account of the pulmonary complications without reference to the importance of the host in their determination. Pregnancy, heart disease and chronic bronchitis are the three chief associates of severe or fatal influenzal pneumonia (Louria, Blumenfeld, Ellis, Kilbourne and Rogers, I959; Robertson, Caley and Moore, 1958). Whether the virus lesions of the respiratory tract cause death from obstructive bronchitis or because of an effect on the circulation remains to be considered.

\section{Cardiac Complications}

It has always been known that patients with existing heart disease such as mitral stenosis, hypertension or ischæmia tolerate influenza poorly. Perhaps the extent of the deterioration likely to occur was not adequately appreciated before 1957 but numerous papers appeared after the first wave indicating the gravity of influenzal pneumonia in cardiac cases. In Leeds the distinctive character of the clinical picture of influenzal pneumonia in mitral stenosis was pictured by Newcombe, Nixon and Thompson (1958). Severe dyspnœa, hæmoptysis and congestive heart failure were noted. Radiological opacities of a multiple and ill-defined character resembling pulmonary œdema were seen. Three of the nine patients died. The effect of influenza in patients with other forms of pre-existing heart disease has not attracted so much attention as that of mitral stenosis. However, congestive cardiac failure at times is clearly dated from an attack of influenza in patients with any form of heart disease and particularly with chronic cor pulmonale. The mechanism of this does not appear to be a specific effect of influenza virus infection.

Cardiac complications in patients without preexisting heart disease are, however, uncommon. Pericarditis and myocarditis have been described infrequently (Finland, Parker, Barnes and Joliffe, 1945). Adams (1959) described eight cases of socalled benign non-specific pericarditis occurring after either influenza B or influenza $A$ infection. Bacteria did not appear to be concerned in these abnormalities but pericarditis certainly occurs in some patients with staphylococcal pneumonia. Studies of the effect of Asian influenza on the normal circulatory system were made by Walsh, Burch, White, Mogabgab and Dietlein (1958). The first study of 30 patients with influenza admitted to hospital included 20 with uncompli- cated disease and ten with pulmonary involve ment. Abnormal electrocardiographic findings: consisting of $T$-wave changes without an impairment of conduction and changes in the vectorcardiogram were noted in a proportion of the patients including uncomplicated cases. Gibson $\stackrel{?}{+}$ Arnold, Craige, and Curnen (1959) studied 87 university students and found 12 with electro흠 cardiograms which were rated abrormal becauses of S-T segment deviations, T-wave depression? and arrhythmias. Four of the 12 patients hac abnormalities only during convalescence. TheseAmerican authors think that their findings support the existence of a myocarditis due to influenza virus which is clinically overlooked. Probably this is a matter requiring much more work foo though influenza virus has been recovered from? the heart muscle in patients dying from influenzato pneumonia (Kaji, Oseasohn, Jordan and Dingle 1959) it seems probable that this is due to an agonal viræmia. The more plausible effect of 'toxæmia' is equally difficult to sustain. Apar ${ }^{\circ}$ from its pyrogenic action, influenza virus requires to be given in enormous doses to demonstrate $\overrightarrow{\vec{O}}$ toxic effect in mice and then the liver, the braim and lung appear to be the chief targets (Henle and Henle, 1946).

\section{Neurological Complications}

The evidence for association between influetis and neurological disease has in the past berp circumstantial and untrustworthy because of thes lack of laboratory data. Encephalitis as a cause of death has occurred after 0.8 to 1.2 cases per $1,00 \%$ influenza deaths in the years from 1950 onwards $\stackrel{\mathbb{D}}{\mathbb{D}}$ This is probably similar to the reported frequency of measles encephalitis of I per I,000 cases though these are not of course all fatal. In 1957, a new phenomenon appeared, namely an incidence of fatal encephalitis of 3.6 per 1,000 influenza deaths Numerous articles appeared in the press and․․ none were more convincing than the papers by Flewett and Hoult (1958) and Hoult and Flewet? (1960) from this hospital. I shall follow theif suggestions for the classification of cases of encephalitis occurring synchronously with influenza, cases of encephalitis occurring thres days to two weeks after influenza, the Guillain Barré syndrome and cases of a mixed characte probably with only a coincidental link witk influenza. It is chiefly cases of a synchronous character which have been widely described a仓 acute influenzal encephalitis by other authorso This disease is sometimes hæmorrhagic in characo ter but lesions at autopsy are not impressive ever though influenza virus was recovered from eithef brain or CSF in isolated instances. It is generallyo agreed that the post-influenzal cases of encephaliti? are of the demyelinating type which occur afte? 
other acute infections such as measles, rubella and varicella. Their relationship to the virus infection is obscure. Thirdly, Guillain-Barré syndrome certainly has no specific relation to influenza and may indeed have an origin in autoimmunization. Nevertheless, Wells, James and Evans (1959) recovered influenza virus from the CSF taken at autopsy in two fatal cases occurring in Cardiff in 1957. I find the whole question of virus recovery from post-mortem specimens difficult to evaluate unless the brain is opened prior to the examination of the thorax. This has seldom been done.

Finally, there seems no particular point in describing the various types of neurological disease casually related to influenza. I would like to point out the undoubted existence of acute organic psychoses in influenza particularly in adults in 1957. Delirium, mania and convulsions with few or absent neurological signs were all described (Friedman and Cancellieri, 1958) and may perhaps represent a true toxic effect of influenza. One can only conclude by reference to the extremely low frequency of all neurological abnormalities occurring as complications of influenza. It is difficult to maintain the perspective required to contrast their rarity with the frequency of depression during convalescence particularly in the elderly.

\section{Conclusion}

Influenza virus infection falls on the healthy and abnormal population equally. Though it causes complications much more frequently in those with pre-existing heart or chest disease, its effect as an initiator of disease of the lungs in those with previously good health must not be overlooked. This summary of the chief clinical complications has left little time to refer to otitis media, labyrinthitis or sinusitis. Of these perhaps acute labyrinthitis is a syndrome following upper respiratory disease which has a particularly striking character. Like otitis media however, there is no evidence linking it specifically with influenza virus.

\section{REFERENCES}

Adams, C. W. (1959): Post-viral Myopericarditis Associated with the Influenza Virus: Report of Eight Cases, Amer. F. Cardiol., 4,56 .

Eickhoff, T. C., Sherman, I. L., and Serfling, R. C. (196r): Observations on Excess Mortality Associated with Epidemic Influenza, F. Amer. med. Ass., r76, 776.

Finland, M., Parker, F., Jr., Barnes, M. W., and Joliffe, L. S. (1945): Acute Myocarditis in Influenza A Infeco tions: Two Cases of Non-bacterial Myocarditis, with Isolation of Virus from the Lungs, Amer. F. med. Sci., 209, 455 .

Flewet, T. H., and Hoult, J. G. (1958): Influenzal Encephalopathy and Post-influenza Encephalitis, Lancet, ii, r r

Friedman, J. H., and Cancellieri, R. (1958): Central Nervous System Complications of Asian Influenza, $N$. $Y$. St. $\mathcal{F}$. Med., 58, 859 .

Gibson, T. C., Arnold, J., Craige, E., and Curnen, E. C. (1959): Electrocardiographic Studies in Asian Influenza, Amer. Heart Y., 57, 661.

Henle, G., and Henle, W. (1946): Studies on the Toxicity of Influenza Virus: I. The Effect of Intracerebral Injection of Influenza Viruses, $\mathscr{F}$. exp. Med., 84, 623.

Hers, J. F. Ph., Goslings, W. R. O., Masurel, N., and Mulder, J. (1957): Death from Asiatic Influenza in the Netherlands, Lancet, ii, I 164 .

- Masurel, N., and Mulder, J. (1958): Bacteriology and Histopathology of the Respiratory Tract and Lungs in Fatal Asian Influenza, Ibid., ii, I 141 .

Hoult, J. G., and FleweTt, T. H. (1960): Influenzal Encephalopathy and Post-influenzal Encephalitis: Histological and Other Observations, Brit. med. $\mathcal{F}$., i, 1847.

Kaji, M., Oseasohn, R., JoRDan, W. S., Jr., and Dingle, J. H. (1959): Isolation of Asian Virus from Extrapulmonary Tissues in Fatal Asian Influenza, Proc. Soc. exp. Biol. (N.Y.), roo, 272.

Kilbourne, E. D. (1960): 'Ciba Foundation Study Group No. 4: Virus Virulence and Pathogenicity', p. $58 . \quad$ London: Churchill.

Louria, D. B., Blumenfeld, H. L., Ellis, J. T., Kilbourne, E. D., and Rogers, D. E. (i959): Studies on Influenza in the Pandemic of 1957-58: II. Pulmonary Complications of Influenza, $\mathcal{F}$. clin. Invest., $38,213$.

Newcombe, C. P., Nixon, P. G. F., and Thompson, H. (1958): Influenzal Pneumonia in Mitral Stenosis, Acta med. scand., I62, $44 \mathrm{I}$.

Report of the Public Health Laboratory Service (1958): Deaths from Asian Influenza, i 957, Brit. med. F., i, 9 i 5.

Robertson, L., CALey, J. P., and Moore, J. (1958): Importance of Staphylococcus aureus in Pneumonia in the I957 Epidemic of Influenza A, Lancet, ii, 233.

StuART-Harris, C. H. (1953): 'Influenza and Other Infections of the Respiratory Tract'. London: Edward Arnold.

- Andrewes, C. H., and Smith, W. (1938): A Study of Epidemic Influenza with Special Reference to the 1936-37 Epidemic, Med. Res. Counc. (Lond) Spec. Rep. Ser. No. 228.

Walsh, J., Burch, G. E., White, A., Mogabgab, W., and Dietlein, L. (1958): A Study of the Effects of Type A (Asian Strain) Influenza on the Cardiovascular System of Man, Ann. intern. Med., 49, 502.

-, Dietlein, L. F., Low, F. H., Burch, G. E., and MogabGab, W. J. (196r): Bronchotracheal Response in Human Influenza: Type A, Asian Strain, as Studied by Light and Electron Microscopic Examination of Bronchoscopic Biopsies, Arch. intern. Med., 108, 376.

Wells, C. E. C., James, W. R. L., and Evans, A. D. (1959): 'Guillain-Barré Syndrome and Virus of Influenza A (Asian Strain), Arch. Neurol. Psychiat. (Chicago), 81, 699.

For the subsequent discussion see p. 590 